\title{
Factors Affecting Implementation of Nursing Process: Nurses' Perspective
}

\author{
Fadia A. Abdelkader ${ }^{1}$, Walaa N.E. Othman ${ }^{2}$ \\ ${ }^{1}$ Critical Care Nursing Department, Faculty of Nursing-Mansoura University \\ ${ }^{2}$ Medical-Surgical Nursing Department, Faculty of Nursing-Mansoura University
}

\begin{abstract}
:
Background: Application of nursing process helps the nurses to utilize critical thinking for decision making and care activities. There are many factors that interferes the implementation of the nursing process.

The aim of study: to identify barriers in implementation of the nursing process from the standpoint of nurses in different settings of Main University hospital, Mansoura.

Material \& Methods: A descriptive design was used to conduct this study on 100 nurses worked at the pervious setting were included in the study. Two tools were utilized in

The Present Study: nursing process questionnaire and factors affecting the application of nursing process. Results: The factors that affecting implementation of nursing process were lack of sufficient enthusiasm in using the nursing process, shortage of nursing staff, no format for writing, lack of follow up and monitoring, no adequate time for using, lack of attention to its importance, deficient in clear instruction, inadequate education, and have no believe in applying the patient care according to the nursing process.

Conclusion: It is possible to recommend the hospitals to seek means to upgrade the knowledge of their nurses on the nursing process and utilizing nursing process which reflect the quality of patient care.
\end{abstract}

Keywords: Nursing process, implementation, factors affecting.

\section{Introduction}

The nursing care guided by the nursing process (NP) principles the planning of actions, the interventions, the evaluation and specific goals recognized for each patient. The nursing process consider a problem solving method which is useful to meet the community health and care needs. Application of NP helps the nurses to utilize critical thinking for decision making. [1]

The nursing process (NP) is generally viewed as a tool for planning and providing patient care. The nursing process is synonymous within the discipline of nursing. It is an organized, systematic approach used by nurses to meet the individualized health care needs of their patients. care as a process. [2]

Assessment, diagnosis, planning, implementation and evaluation are steps of the nursing process accordingly. Assessment is an organized dynamic process including: systematically collecting data, and ordering the collected data, and documenting the data in a retrievable way. Subjective and objective data are collected from different sources the nurse emphasizes on eliciting a profile of the patient that supplies a sense of the patient's overall health status, providing a picture of the patient. [3]

Diagnosis/need identification means the analysis of collected data to recognize the patient's needs or problems, also called the nursing diagnosis. The purpose of this step is to draw a whole picture regarding the patient's specific needs of concern so which effective care can be planned and given. [4] Planning contains setting priorities, establishing goals, considering proper patient outcomes, and determining exact nursing interventions. These actions are accepted as the plan of care. [3]

Implementation occurs when the plan of care is put into action, and the nurse performs the planned interventions. Individual knowledge and expertise and agency routines allow the flexibility that is necessary to adapt to the changing needs of the patient. [5] Evaluation is accomplished by determining the patient's progress toward attaining the known outcomes and by monitoring the patient's reaction to efficiency of the preferred nursing interventions for the reason of altering the plan as indicated. [6]

Nursing process is a step by step series of actions that create something or that lead to a particular result related to health of a patient. It is a matter of fact that nursing process is the center of nursing practice where professional nurses must be expert. This process has its steps that guide nurses in description holistic nursing care to be demonstrated excellently for this is the foundation of quality nursing care to customers. in addition to, interaction is significant in between the patient and the nurse because it is the only way of gaining cooperation in time nursing care is being implemented. On Orlando's Deliberative Nursing Process Theory, the focus is on the interaction between the nurse and patient, perception validation, and the use of the nursing process to create optimistic outcomes or patient progress. [4] 
Despite, the importance of studying and using the nursing process, the nurses use problem solving process in order to arrange and give nursing services. NP helps the nurse to use critical thinking for clinical judgments. [7] Principles for implementing the nursing process is the systematic registration. Consequently, recognizing barriers in accomplishment of the nursing process in Mansoura hospitals seems needed. So, this study aimed to identify barriers in implementation of the NP from the standpoint of nurses in chosen ICU, medical, surgical and orthopedic wards of Main University hospital, Mansora, EGYPT so that the outcome of this study can be helpful in identifying current barriers and implementation of the nursing process in our country will be easy. [8]

There are many barriers that interferes the implementation of the nursing process, some of these barriers related to individual factors and the others related to management or policy factors. Individual factors as insufficient information, no belief in doing the patient care according to it, lack of sufficient motivation in doing NP, lack of enough skill for doing NP, uninteresting in doing the NP, uncooperation among the nurses. [8]

While the management factors as: repetitious replacement of the nurses, Shortage of nursing staff, no format for writing, lack of monitoring on nursing process, there no necessary facilities, lack of enough time, lack of attention to its importance, lack of specific instructions, lack of education, lack of enough trained nurses, hospital policies in non-implementation of the nursing process. $[8,9]$

\section{Materials and Methods}

The study design is a descriptive study, designed to identify the factors affecting the application of nursing process in clinical setting. The study was conducted in ICU, orthopedic, medical, and surgical department at Mansoura University Hospital. A convenience sample of 100 nurses of both sexes worked at the pervious setting were included in the study, the nurses refuse to sharing in the study will be excluded from the study. Two tools were utilized in the present study after reviewing the related literatures.

Tool I: Nursing Process Questionnaire: This tool was developed by the researcher after reviewing the related literatures (and used to evaluate the nurse's knowledge of nursing process and include two parts as follow:

Part one: "General Characteristics of Nurses": This part include the following data, age, gender, ward, educational level, position, years of experience, implementation of nursing process.

Part two "Nursing Process Questionnaire": this part include (23 question) to assess the level of nurse's knowledge of nursing process in the form of MCQ.

\section{Tool II: Factors affecting the application of nursing process}

This tool was modified from (Akbari \& Shamsi, 2011), [15] and used to identify the factors affecting the application of nursing process from nurse's point of view, these factors are (17) factors and each nurse are asked about each factors with Yes (equal 1) and No (equal 0) .

\section{Methods}

- Permission to conduct the study was obtained from responsible authorities of the study area (Mansoura University Hospital) after clear explanation to the aim of the study.

- Verbal consent approval was obtained from each participating nurse. Anonymity, privacy, safety, confidentiality and the right to withdraw from the study at any time were assured.

- Clarification of the study purpose was done. The researcher emphasized that participation is absolutely voluntary.

- All tools were tested for content validity by 5 professors in the field from faculty of nursing Mansoura University and the necessary modifications were done accordingly.

- Data collection extended over a period of two month from 1/9/2016 to 1/11/2016

- Nurses agreed to participate in the study were interviewed and asked to fill the nursing process questionnaire using tool (I), then the nurses choose the factors affecting the application of nursing process using tool (II).

\section{Result}

The findings of the study will be presented in five tables: (1)Distribution according to their sociodemographic characteristics, (2) Distribution according to their knowledge assessment regarding nursing process, (3) Distribution of groups according to their knowledge assessment result, (4) Relationship between knowledge assessment result of the studied group as regards work place, age group, gender, educational level, position, and years of experience through the period of the study, (5) Factors affecting nursing process implementation from nurses' point of view.

Table (1) shows the distribution of studied group according to their demographic characteristics. A total of 100 nurses were enrolled in the study. The majority of nurses included in the study $51.0 \%$ have been working at ICU. The majority of the studied group $43.0 \%$ aged from $35-39$ years. Female were more included in the studied group, they constituted $91.0 \%$ of all study sample. Concerning level of education, the majority of the 
studied sample $94.0 \%$ was holding a bachelor degree of nursing. Regarding position of studied nurses, the table also shows that $66.0 \%$ of them were a head nurse. In relation to numbers of experience years in active service, the table reveals that nearly half of the studied sample $47.0 \%$ has years of experience ranged from 10-14 years with mean years 10.40 \pm 3.10 . The table also showed that, all of the studied nurses $100.0 \%$ have no implementation of nursing process in their clinical setting.

Table (1): Distribution of studied group according to demographic characteristics $(\mathrm{N}=100)$

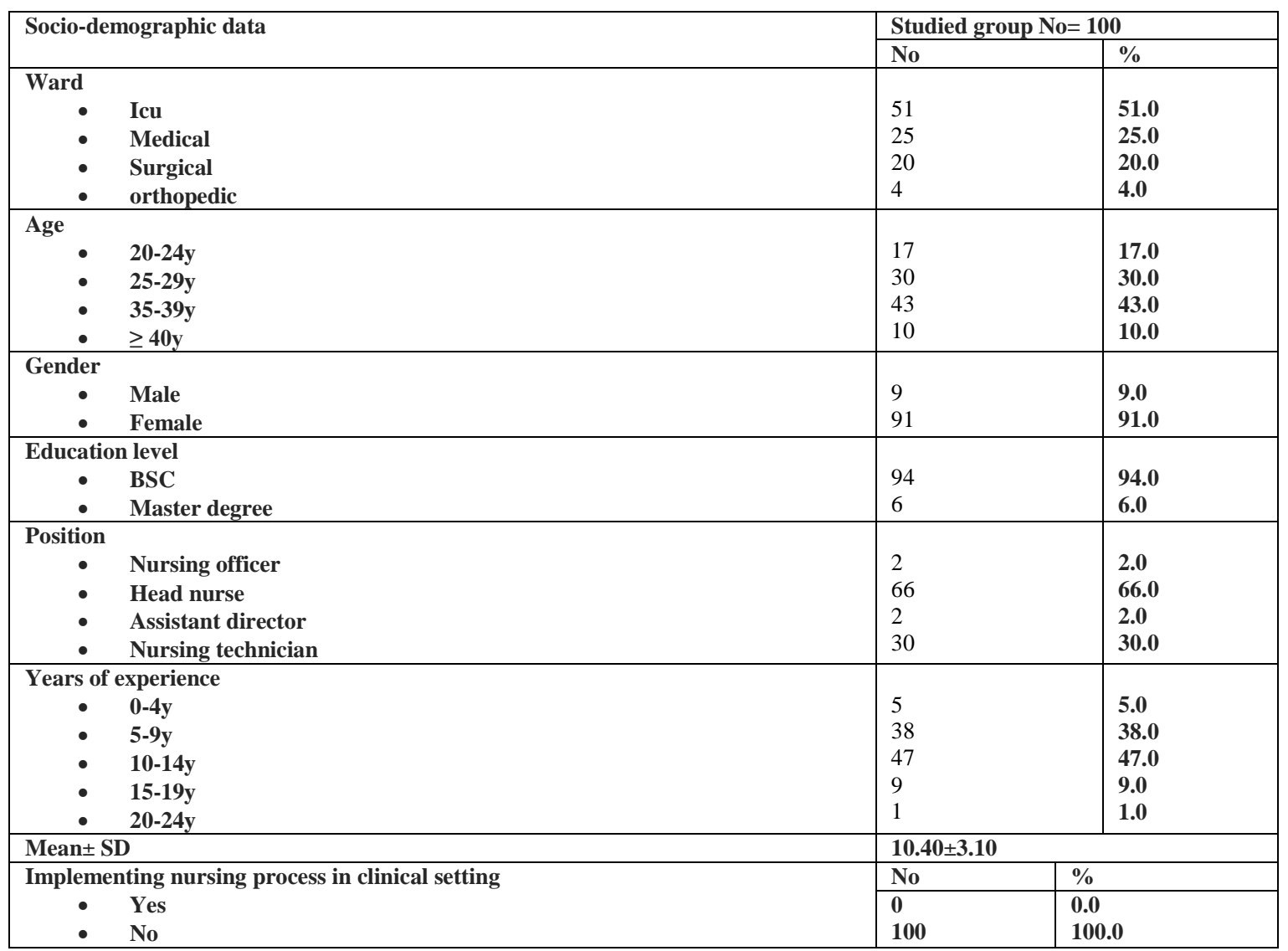

Table (2) shows the distribution of studied groups according to their knowledge assessment regarding nursing process. As regards (nursing process utilization) question, the majority of sample $99.0 \%$ have correct answer. in relation to (nursing process steps) question, the majority of sample $97.0 \%$ have correct answer. The table also shows that, $98.0 \%$ of the studied sample has correct answer regarding (assessment step) question. In relation to (NANDA) question, the majority of sample $85.0 \%$ has correct answer. Concerning (establishing nursing diagnosis) question, only $9.0 \%$ of sample have correct answer. The majority of the studied sample shows the highest percent $88.0 \%$ and $93.0 \%$ respectively regarding (nursing diagnosis completeness \& developing plan) questions have correct answer. As regards (goals established in a plan \& essential component of written goal) questions, it was observed that, the majority of sample $100.0 \% \& 88.0 \%$ respectively have incorrect answer.

Table (2): Distribution of studied groups according to their knowledge assessment answers regarding nursing process quiz

\begin{tabular}{|c|c|c|}
\hline \multirow[t]{2}{*}{ Nursing Process Items } & \multicolumn{2}{|c|}{ Correct Answer } \\
\hline & No & $\%$ \\
\hline 1. Nursing process utilization & 99 & 99.0 \\
\hline 2. $\quad$ Nursing process steps & 97 & 97.0 \\
\hline 3. $\quad$ Assessment step & 98 & 98.0 \\
\hline 4. $\quad$ Objective data & 95 & 95.0 \\
\hline 5. $\quad$ Subjective data & 94 & 94.0 \\
\hline 6. Analysis of objective and subjective data & 100 & 100.0 \\
\hline 7. $\quad$ NANDA & 85 & 85.0 \\
\hline 8. $\quad$ Establishing nursing diagnosis & 9 & 9.0 \\
\hline 9. $\quad$ Behavior observed & 84 & 84.0 \\
\hline
\end{tabular}


Factors Affecting Implementation Of Nursing Process: Nurses' Perspective

\begin{tabular}{|c|c|c|}
\hline 10. Nursing diagnosis completeness & 88 & 88.0 \\
\hline 11. Developing plan & 93 & 93.0 \\
\hline 12. Goals established in a plan & $\mathbf{0}$ & 0.0 \\
\hline 13. Essential component of written goals & 12 & 12.0 \\
\hline 14. The patient and the family & 96 & 96.0 \\
\hline 15. Patient outcome & 89 & 89.0 \\
\hline 16. Other important outcome & 80 & 80.0 \\
\hline 17. The plan of care & 72 & 72.0 \\
\hline 18. Not be considered an intervention & $\mathbf{0}$ & 0.0 \\
\hline 19. Open communication & 86 & 86.0 \\
\hline 20. The evaluation phase & 93 & 93.0 \\
\hline 21. Questions during evaluation phase & 76 & 76.0 \\
\hline 22. If the plan is not working & 12 & $\mathbf{1 2 . 0}$ \\
\hline 23. Data support an additional diagnosis & 11 & $\mathbf{1 1 . 0}$ \\
\hline
\end{tabular}

Table (3) shows the distribution of studied group according to their knowledge assessment result. It was found that, the majority of the studied sample $88.0 \%$ have average knowledge score, which ranged from $11.5-<15$. While only $4.0 \%$ of total studied sample have poor knowledge score < 11.5(Total: 23 score).

Table (3): Distribution of studied group according to their knowledge assessment outcome $(\mathrm{No}=100)$

\begin{tabular}{|c|l|l|}
\hline knowledge assessment outcome & \multicolumn{2}{|c|}{ Studied group No=100 } \\
\cline { 2 - 3 } & No & $\%$ \\
\hline Poor $<11.5$ & 4 & 4.0 \\
Average 11.5- $<15$ & 88 & 88.0 \\
Good $\geq 15$ & 8 & 8.0 \\
\hline Total score $=23$ & 100 & 100 \\
\hline
\end{tabular}

Table (4) show relationship between knowledge assessment results of studied group as regards work place. The table reveals that the ICU staff had (50\%) average knowledge score, while the knowledge score of medical staff was good $(62.5 \%)$. on other hand, surgical ward had $(22.7 \%)$ average knowledge score, while $(4.5 \%)$ of nursing staff at orthopedic unit had average knowledge score. A significant association between knowledge score and working in different departments was observed $(\mathrm{p}=0.084)$.

The table shows that the half of nursing staff between ( 20-24 years) (50\%) had good knowledge score, while the knowledge score of nursing staff between (25-29 years old) was good (50\%). on other hand, nearly of half of nursing staff between (35-39 years old) (47.7) had average knowledge score, and $25 \%$ of nursing staff $\geq 40$ had average knowledge score. A significant association between knowledge score and age group was observed $(\mathrm{p}=0.032)$. The table reveals that, the $89.9 \%$ of female nursing staff had average knowledge score. The table shows that, the $93.2 \%$ of BSC nursing staff had average knowledge score. The table shows that (75\%) of the knowledge score of head nurse was good. The table reveals that the ICU staff work at the hospital between 5-9 years was (75\%) good knowledge score, while the knowledge score of staff work at the hospital between 10-14 years was average (50\%). A significant association between knowledge score and Years of experience was observed (chi-square $=0.039$ ).

Table (4) Percentage distribution of nurses' knowledge score regarding working department

\begin{tabular}{|c|c|c|c|c|c|c|c|}
\hline \multirow[t]{3}{*}{ Departments } & \multicolumn{6}{|c|}{ Knowledge } & \multirow[t]{3}{*}{ Test } \\
\hline & \multicolumn{2}{|c|}{ Poor } & \multicolumn{2}{|c|}{ Average } & \multicolumn{2}{|c|}{ Good } & \\
\hline & No & $\%$ & No. & $\%$ & No. & $\%$ & \\
\hline ICU & 4 & 100 & 44 & 50 & 3 & 37.5 & \multirow{4}{*}{$\begin{array}{l}\text { Chi-Square } \\
0.084\end{array}$} \\
\hline Medical & 0 & 0 & 20 & 22.7 & 5 & 62.5 & \\
\hline Surgical & 0 & 0 & 20 & 22.7 & 0 & 0 & \\
\hline Orthopedic & 0 & 0 & 4 & 4.5 & 0 & 0 & \\
\hline $\begin{array}{l}\text { Age Group } \\
20-24\end{array}$ & 0 & 0 & 13 & 14.8 & 4 & 50 & \multirow{4}{*}{0.032} \\
\hline $25-29$ & 2 & 50 & 24 & 27.3 & 4 & 50 & \\
\hline $35-39$ & 1 & 25 & 42 & 47.7 & 0 & 0 & \\
\hline$\geq 40$ & 1 & 25 & 9 & 10.2 & 0 & 0 & \\
\hline $\begin{array}{l}\text { Gender } \\
\text { Female }\end{array}$ & 4 & 0 & 79 & 89.9 & 8 & 100 & \multirow[t]{2}{*}{0.509} \\
\hline Male & 0 & 0 & 9 & 10.2 & 0 & 0 & \\
\hline Education BSC & 4 & 100 & 82 & 93.2 & 8 & 100 & \multirow[b]{2}{*}{0.647} \\
\hline Master & 0 & 0 & 6 & 6.8 & 0 & 0 & \\
\hline Position Nurse Officer & 0 & 0 & 2 & 2.3 & 0 & 0 & \multirow[b]{4}{*}{0.836} \\
\hline Head Nurse & 4 & 100 & 56 & 63.6 & 6 & 75 & \\
\hline Assistant Director & 0 & 0 & 2 & 2.3 & 0 & 0 & \\
\hline Nursing Technician & 0 & 0 & 28 & 31.8 & 2 & 25 & \\
\hline
\end{tabular}


Factors Affecting Implementation Of Nursing Process: Nurses' Perspective

\begin{tabular}{|l|l|l|l|l|l|l|l|}
\hline $\begin{array}{l}\text { Years of experience } \\
0-4\end{array}$ & 0 & 0 & 3 & 3.4 & 2 & 25 & 0.039 \\
\hline $5-9$ & 1 & 25 & 31 & 35.2 & 6 & 75 & \\
\hline $10-14$ & 3 & 75 & 44 & 50 & 0 & 0 \\
\hline $15-19$ & 0 & 0 & 9 & 10.2 & 0 & 0 & \\
\hline $20-24$ & 0 & 0 & 1 & 1.1 & 0 & 0 & \\
\hline
\end{tabular}

Table (5) demonstrates the factors affecting nursing process implementation from nurses' point of view. It was founded that, more than the half of nurses $63.0 \%$ have insufficient information regarding nursing process. The table also showed, the majority of nurses $76.0 \%$ have no idea in applying it. All studied nurses $100.0 \%$ have no sufficient enthusiasm in using the nursing process, shortage of nursing staff, no format for writing Nursing process, no follow up by the authorities, inadequate time for using it, no attention to its importance by the nursing authorities, and deficient in clear instruction for applying the nursing process by the authorities respectively. The majority of nurses $64.0 \%$ have no problem in implementing nursing process related to repetitious replacement of the nurses. The finding showed that, $63.0 \%$ have no interesting in using the nursing process. The table showed that, $93.0 \%$ of nurses have no adequate education in the nursing process. Regarding hospital policy in non-implementation of the nursing process, $53.0 \%$ of nurses agree about hospital policy in non-implementation of the nursing process.

Table (5): factors affecting nursing process implementation from nurses' point of view

\begin{tabular}{|l|l|l|}
\hline Factors affecting nursing process implementation & Yes \\
\cline { 2 - 4 } & No & $\%$ \\
\hline 1. Lack of sufficient information & 63 & 63.0 \\
\hline 2. No belief in deliver patient care according to it & 76 & 76.0 \\
\hline 3. No enough motivation in using it & 100 & 100.0 \\
\hline 4. Inadequate skillfulness for applying it & 80 & 80.0 \\
\hline 5. No interesting in using it & 63 & 63.0 \\
\hline 6. Lack of cooperation between the nurses & 39 & 39.0 \\
\hline 7. Repetitious replacement of the nurses & 36 & 36.0 \\
\hline 8. Shortage of nursing staff & 100 & 100.0 \\
\hline 9. No format for writing Nursing process & 100 & 100.0 \\
\hline 10. No follow up by the authorities & 100 & 100.0 \\
\hline 11. Not providing necessary facilities for doing the nursing process by the authorities & 0 & 0.0 \\
\hline 12. No enough time for applying it & 100 & 100.0 \\
\hline 13. No attention to its importance by authorities & 100 & 100.0 \\
\hline 14. No specific training for applying it by the authorities & 100 & 100.0 \\
\hline 15. Lack of education of nursing process principle by the authorities & 63 & 63.0 \\
\hline 16. No enough qualified nurses in it & 93 & 93.0 \\
\hline 17. Hospital rules in non-implementation of it & 53 & 53.0 \\
\hline
\end{tabular}

\section{Discussion}

The aim of this study was to identify factors affecting implementation of nursing process: nurses' perspective. The socio-demographic background of the present study showed that, the majority of nurses included in the study $51.0 \%$ have been working at ICU. The majority of the studied group $43.0 \%$ aged from 35 39 years while only $10.0 \%$ were 40 years and more. Female were more included in the studied group, they constituted $91.0 \%$ of all study sample. Concerning level of education, the majority of the studied sample $94.0 \%$ was holding a bachelor degree of nursing while only $6.0 \%$ of them were having master degree. Regarding position of studied nurses, the table also shows that $66.0 \%$ of them were a head nurse comparing to the lowest percent $2.0 \%$ were a nursing officer and an assistant director. In relation to numbers of experience years in active service, the table reveals that nearly half of the studied sample $47.0 \%$ has years of experience ranged from 10-14 years with mean years $10.40 \pm 3.10$.

Regarding nurses' knowledge related to nursing process, the study noted that, the majority of the studied sample $88.0 \%$ have average knowledge score, which ranged from $11.5-<15$. While only $4.0 \%$ of total studied sample have poor knowledge score < 11.5 (Total: 23 score). This agreed with Fisseha et al, 2014 [10] who noted that, knowledge is one of the mainly important factors for implementation of nursing process. The result of this study also agreed with a study conducted in Brazil, which indicated knowledge is one of several factors that interfere in the efficient implementation of the nursing process [11].

The relation between knowledge and the nurses' work place, the present study reveals that the ICU staff had $(50 \%)$ average knowledge score, while the knowledge score of medical staff was good $(62.5 \%)$. on other hand, surgical ward had (22.7\%) average knowledge score, A significant association between knowledge score and working in different departments was observed $(\mathrm{p}=0.084)$. this findings come agree with Roberts, 2000 
[12], results who suggested that, the clinical environment has a potentially significant role to play in both nurses' perceptions and use of the nursing process.

The relation between knowledge and the nurses' age group and years of experience, the majority of the studied group 47.0\% aged from 35-39 years had average knowledge score, A significant association between knowledge score and age group was observed $(p=0.032)$. The study also reveals that, half of the studied sample $50.0 \%$ has years of experience ranged from 10-14 years. A significant association between knowledge score and Years of experience was observed (chi-square $=0.039$ ). These results in agreement with Dousouri, 2010 [13], who noted that nurses regardless their category with educational level ,age and experience had a generally very good knowledge regarding the nursing process.

Factor affecting implementation of nursing process from nurses' point of view, the study showed that $63.0 \%$ have lack of sufficient information regarding nursing process. The study result also showed that, $100.0 \%$ have no enough time for applying it. These findings come agree with McKenna et al, 2004 [11], who noted that, the majority of the nurses have lack of knowledge and lack of enough time for applying it, as mainly significant barriers, which are in agreement with the results of the current study.

Lukes, 2010 [14] also mentioned that, the nurses be trained nursing process when they have only one patient but when patients' numbers increase, they couldn't utilize it. On the other hand, Akbari \& Shamsi, 2011[15] noted that, one of the other reasons in lack of application of the nursing process in intensive care units could be due to excess number of the patients and shortage of nurses. Therefore, nurses do not have enough time to use this systematic method.

The present study presented that, the majority of nurses $76.0 \%$ have no reliance in caring the patient according to the nursing process. This agreed with Haghighi Moghaddam et al, 2004 [16], who mentioned that, no enough information about the conception of it and have no belief in applying it as the majority essential barrier. Additionally, lack of support of the authorities from use of the nursing process is the other administration factor, which can be related to deficient in knowledge about the significance and effect of this process on increasing health care power [15].

The finding of the study showed that, $63.0 \%$ of nurses agree about lack of education of nursing process principle by the authorities. This come agree with Hasson\& Arnetz, 2009 [17], who found that, proper learning of appliance of it helps in additional rising of nursing discipline and increase in their involvement in enhancing the quality of the care.

The current study also showed that, $93.0 \%$ of nurses have no sufficient qualified nurses in the nursing process. This agree with Hughes and Young, 2010 [18], who suggests that as nurses gain more experience in nursing process application, they develop better ways of managing the error and take appropriate measures to ensure that they do not make the same error in the future and promoting the quality of patient care.

\section{Conclusions}

The nursing process is a widely accepted method and has been suggested as a scientific method to guide procedures and qualify nursing care. More recently, the process has been defined as a systematic and dynamic way to deliver nursing care, operating through five interrelated steps: assessment, diagnosis, planning, implementation, and evaluation [19]. Lack of utilizing of the nursing process can decrease the quality of care. Nurses of the current study reported that factors such as lack of knowledge, high patient nurse ratio/work load, and lack of educating, training and motivating factors affected the application of the nursing process. It is possible to recommend the hospitals to look for resources to promote the awareness of their nurses on it and its utilization.

\section{Recommendations}

- Introduction of educational programs will enhance nurses' ability to use nursing the process to improve the quality of patient's care.

- Motivation of nurses is very important in improving care planning systems that would further promote consistency in the process.

- Programs to train, improve and update the nurses working in clinical health settings with current innovations in the nursing process should be implement.

\section{References}

[1]. Cruz, D. Guedes, E. Santos, A. Sousa, R. Turrini, T. Maia, M. Araújo, N., Nursing process documentation: rationale and methods of analytical study, Rev Bras Enferm, (1), 2016, 183-189.

[2]. Yildirim, B., Özkahraman, S., Critical Thinking in Nursing Process and Education, International Journal of Humanities and Social Science, 1(13), 2011, 257-262.

[3]. Newfield, SA. Hinz, M. D. Scott Tilley, D. Sridaromont, K. L. Joy Maramba, P., 2007 Cox's clinical applications of nursing diagnosis Adult, Child, Women's, Mental Health, Gerontic, and Home Health Considerations. F. A. Davis Company. 
[4]. Doenges, ME., Moorhouse, MF., Murr, AC., 2008 Nurses pocket guide diagnosis, prioritized interventions and rationales. F. A. Davis Company.

[5]. Carpenito, LJ., 2009 Nursing Care Plans \& Documentation: Nursing Diagnoses and Collaborative Problems. Lippincott Williams \& Wilkins

[6]. De Medeiros Dantas, AL., de Almeida Medeiros, AB., de Araújo Olímpio, J., de Sá Tinôco, JD., da Conceição Dias Fernandes, MI. and de Carvalho Lira, ALB., Nursing Diagnoses of the Domain Safety/Protection and Socioeconomic and Clinical Aspects of Critical Patients. Open Journal of Nursing, 6, 2016, 314-322.

[7]. Potter, PA., Perry, AG., 2007 Basic nursing: essentials for practice. Philadelphia: Mosby Elsevier.

[8]. Akbari M., Shamsi A., A Survey on Nursing Process Barriers from the nurses' view of Intensive Care Units. Iranian Journal of Critical Care Nursing. 4(3) 2011, 181-186.

[9]. Mangare N. L., Omondi A. L., Ayieko O. A., Wakasiaka S., Wagoro M. C. A., Implementation of the Nursing Process in Naivasha District Hospital, Kenya, American Journal of Nursing Science, 5(4) 2016, 152-157.

[10]. Fisseha et al, (2014) Application of Nursing Process and Its Affecting Factors among Nurses Working in Mekelle Zone Hospitals, Northern Ethiopia .

[11]. McKenna H, Ashton S, Keeney S (2004) Barriers to evidence based practice in primary care: A review of the literature. Int J Nurs Stud. 41(4):369-78.

[12]. Roberts J. (2000) problem- solving skills of senior student nurses: an exploratory study using simulation. International journal of nursing studies $37,135-143$.

[13]. Dousouri, N.S. (2010): Perception of nurses on the implementation of the nursing process in the Brong-Ahafo Region. Institute for Educational Planning and Administration; http://hdl.handle.net.

[14]. Lukes E. (2010) The nursing process and program planning. AAOHN J. 58(1):5-7.

[15]. Akbari M. MSc., Shamsi A1 MSc . (2011) A Survey on Nursing Process Barriers from the nurses' view of Intensive Care Units Volume 4, Issue 3. Pages: 181-186.

[16]. Haghighi Moghaddam Y. (2004) A survey on nursing process barriers from nurses' view in selected hospitals of Urmia. (MSc Thesis), Urmia Medical University; p.5.

[17]. Hasson H, Arnetz JE. (2009) The impact of an educational intervention on nursing staff ratings of quality of older people care: A prospective, controlled intervention study. Int J Nurs Stud. 46(4):470-8.

[18]. Hughes K., Young W. (2010). The relationship between task complexity and decision making consistency. Research in nursing and health 13, 189-197.

[19]. Carol Taylor C, Lillis C, LeMone P, Lynn P. (2008) Fundamentals of nursing: The art and science of nursing care. 6th ed. Philadelphia: Lippincott Williams \& Wilkins; p.51-9. 